\title{
Micro-CT and histologic analyses of bone surrounding immediately loaded miniscrew implants: Comparing compression and tension loading
}

\author{
Susumu NAKAGAKI ${ }^{1}$, Masahiro IIJIMA¹, Keisuke HANDA², Toshiyuki KOIKE², Yoshitaka YASUDA³, Takashi SAITO² \\ and Itaru MIZOGUCHI \\ ${ }^{1}$ Division of Orthodontics and Dentofacial Orthopedics, Department of Oral Growth and Development, School of Dentistry, Health Sciences University \\ of Hokkaido, Ishikari-Tobetsu, Hokkaido 061-0293, Japan \\ ${ }^{2}$ Division of Clinical Cariology and Endodontology, Department of Oral Rehabilitation, School of Dentistry, Health Sciences University of Hokkaido, \\ Ishikari-Tobetsu, Hokkaido 061-0293, Japan \\ ${ }^{3}$ Yasuda Orthodontic Office, Nishinomiya, Hyogo, 663-8113, Japan \\ Corresponding author, Masahiro IIJIMA; E-mail: iijima@hoku-iryo-u.ac.jp
}

This study investigated the effect of immediate force on bone adaptations surrounding miniscrew implants. Ten miniscrew implants were placed on the mandibles in three beagle dogs. Five pairs of miniscrew implants were immediately loaded with $150 \mathrm{~g}$ of continuous force using nickel-titanium coil springs for 8 weeks. The values of bone mineral density (BMD), bone mineral content (BMC), and bone volume (BV) of cortical and trabecular bone for compression loading and tension loading were obtained by $\mu \mathrm{CT}$ analysis. The percentages of bone-to-implant contact (BIC) in the compression and tension regions for cortical and trabecular bone were obtained by histologic analysis. The BMD values for the compression region of cortical bone were significantly higher compared to the tension region. The BIC values in cortical and trabecular bone at tension and compression regions were similar. In conclusion, immediate loading does not inhibit osseointegration of miniscrew implants but may stimulate bone mineralization.

Keywords: Miniscrew implant, Immediate loading, Micro-CT, BMD

\section{INTRODUCTION}

Anchorage control is an important factor for success in orthodontic treatment. Roberts et al. ${ }^{1)}$ discovered how to use a dental implant as skeletal anchorage without the need for patient compliance for tooth movement in orthodontic treatment, although the technique has disadvantages such as the necessity for a surgical procedure, high cost, and difficulty in hygiene control. Since the miniscrew implant was introduced by Kanomi ${ }^{2}$, various miniscrews have been marketed and are gaining popularity because their small size allows for more placement sites in the oral cavity, less discomfort for patients, an easy surgical procedure, and low $\operatorname{cost}^{3-5)}$. However, one of the major concerns regarding miniscrew implants is their relatively low success rate. A recent systematic review showed that the failure rate of miniscrew implants ranged from $13.4 \%$ to $20.1 \%{ }^{6}$. A variety of factors that may affect the primary stability and success rate of miniscrew implants, such as implant dimension ${ }^{3,7}$, implant length ${ }^{8)}$, insertion orientation ${ }^{9)}$, insertion torque ${ }^{10)}$, and cortical bone thickness ${ }^{11,12)}$, have been investigated. However, since immediate or early loading shortens the treatment period, with great clinical benefits for the orthodontist and patient, the effects of immediate loading have been histologically investigated for both self-tapping and self-drilling miniscrew implants ${ }^{13-17}$. A recent histologic investigation reported that

Color figures can be viewed in the online issue, which is available at J-STAGE.

Received Aug 13, 2013: Accepted Dec 20, 2013

doi:10.4012/dmj.2013-223 JOI JST.JSTAGE/dmj/2013-223 immediate loading does not affect osseointegration of the miniscrew implant ${ }^{15}$. Several studies ${ }^{13,15,17)}$ reported that remodeling or bone apposition was slightly more active in the compressive loaded region than the tension-loaded or unloaded regions. In addition, a recent study ${ }^{18)}$ examined the effect of immediate loading on the biomechanical properties of bone surrounding the miniscrew implant by nanoindentation testing and reported that the implant bone interface region on the compression side of trabecular bone showed significantly greater hardness compared with other locations.

Recent studies ${ }^{19-21)}$ have used microcomputed tomography $(\mu \mathrm{CT})$ to measure the mineral in bone quantitatively. Massey et $a l .{ }^{21)}$ reported significantly greater bone volume fraction around loaded miniscrew implants in the noncortical regions. To better understand how bone adapts to immediate force applied to miniscrew implants, the present study employed a combination of $\mu \mathrm{CT}$ and histologic analyses for miniscrew implants with immediate orthodontic loading.

The aim of the present study was to investigate the effect of immediate force on bone adaptations surrounding the miniscrew implant. We compared the bone response between compression and tension regions using $\mu \mathrm{CT}$ and histologic analyses.

\section{MATERIAL AND METHODS}

Sample preparation

Three healthy male beagle dogs (age, 10-15 months; 


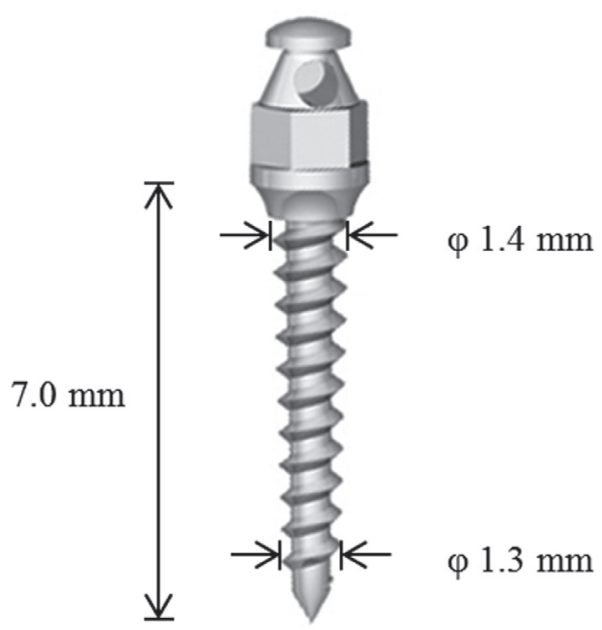

Fig. 1 Morphological features of the miniscrew implants used in the present study.

weight, $\sim 10 \mathrm{~kg}$ ) were selected. They received a soft diet during the experiment. All procedures were approved by the Animal Ethics Committee of Health Sciences University of Hokkaido (No. 063). Ten conical titanium alloy (Ti-6Al-4V) miniscrew implants (AbsoAnchor SH1413-7, Dentos, Daegu, Korea), $1.3 \mathrm{~mm}$ in tip diameter, $1.4 \mathrm{~mm}$ in neck side diameter, and $7 \mathrm{~mm}$ long, were used (Fig. 1). The recipient sites included the attached gingival and movable mucosa in the posterior region $(\sim 5$ $\mathrm{mm}$ apical to the root furcations of the premolars and approximately $3 \mathrm{~mm}$ from the gingival margin between the roots of the premolars) of the mandibular buccal sides.

The dogs were treated with ketamine hydrochloride (Ketalar, Daiichi Sankyo Espha, Tokyo, Japan; $5 \mathrm{mg}$ per $\mathrm{kg}$, i.m.) for analgesia and thiopental sodium (Ravonal, Mitsubishi Tanabe Pharma, Osaka, Japan; $50 \mathrm{mg}$ per $\mathrm{kg}$, i.v.) for anesthesia. Diazepam (Horizon, Astellas Pharma, Tokyo, Japan; $2 \mathrm{mg}$ per $\mathrm{kg}$ ) and atropine sulfate (Mitsubishi Tanabe Pharma; $0.1 \mathrm{mg}$ per $\mathrm{kg}$ ) were given intramuscularly for pre-anesthesia.

All of the miniscrew implants were placed manually with a hand-driver by the same operator (Y.Y.) without drilling a pilot hole. The mobility of the miniscrew implants was checked with dental tweezers immediately after placement and after 8 weeks. Radiographic images were taken to ensure that the miniscrew implants did not contact the roots of the teeth (Fig. 2a). Approximately $150 \mathrm{~g}$ of continuous force (for 8 weeks), which is typical orthodontic force for tooth movement, was immediately loaded on five pairs of miniscrew implants using $\sim 10-\mathrm{mm}$ stretched nickeltitanium closed coil springs (Sentalloy Closed Coil Spring, Tomy International, Tokyo, Japan) (Fig. 2b). The heads of the miniscrew implants were covered with Dura Seal (Reliance Dental, Worth, IL). All miniscrew implants were stable during the experimental period.
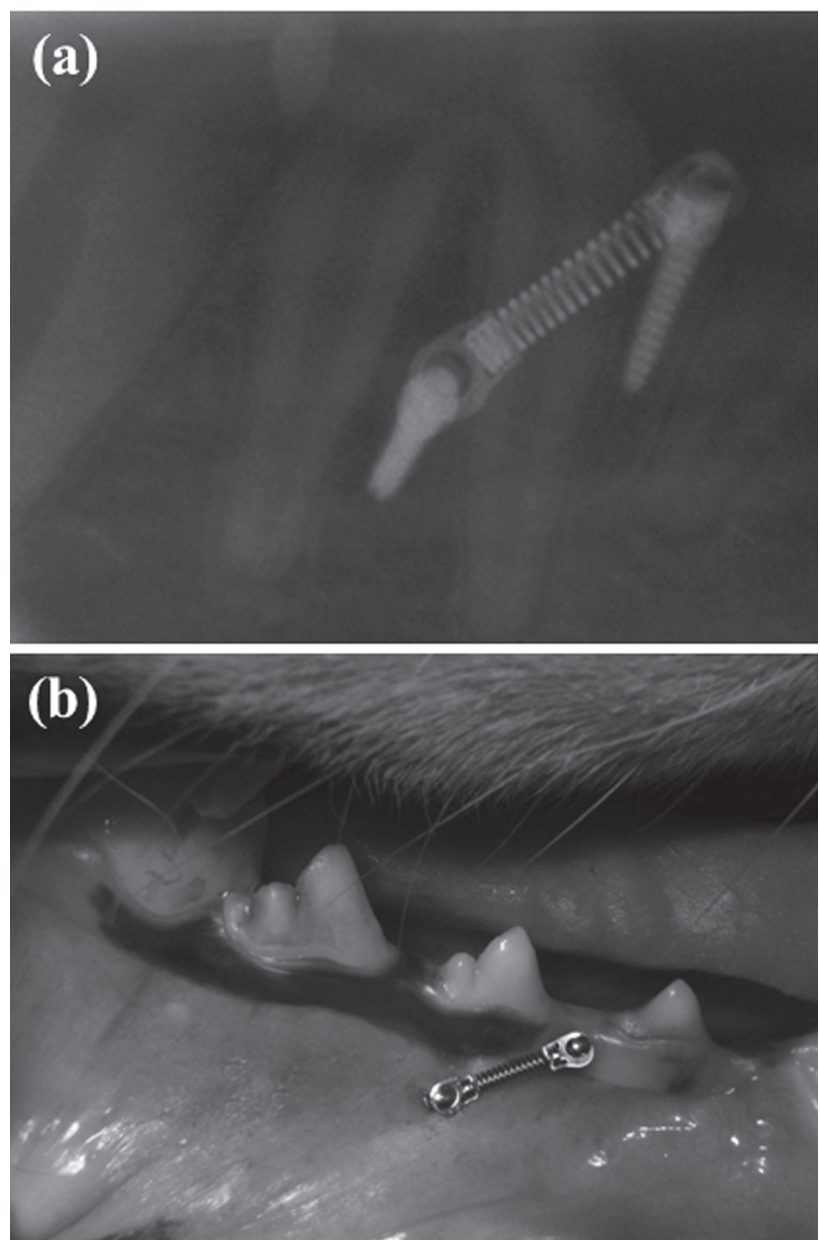

Fig. 2 (a) Radiographic image confirming the recipient site and root proximity. (b) Approximately $150 \mathrm{~g}$ of continuous force was immediately loaded using approximately $10-\mathrm{mm}$ stretched nickel-titanium closed coil spring.

The three dogs were anesthetized and sacrificed after 8 weeks with thiopental sodium (Ravonal, Mitsubishi Tanabe Pharma; $150 \mathrm{mg}$ per kg, i.v.). The mandibular bones including the miniscrew implants were dissected.

\section{$\mu C T$ analysis}

Five miniscrew implants were randomly selected for $\mu \mathrm{CT}$ analysis. The miniscrew implants were carefully removed with a hand-driver, and then the bone, with an approximate size of $3.5 \times 3.5 \times 8.0 \mathrm{~mm}^{3}$ and with the implant hole was sectioned using a slow-speed watercooled diamond saw (Isomet 11-1280, Buehler, Illinois, USA). A scanning of the specimens with a cone-beam $\mu \mathrm{CT}$ scanner was performed along the long axis of the implant hole at room temperature with tube voltage $60 \mathrm{kV}$ and tube current $60 \mu \mathrm{A}$ (TDM1000, Yamato Kagaku, Tokyo, Japan). The specimens were placed in a cylindrical sample holder with a small amount of 


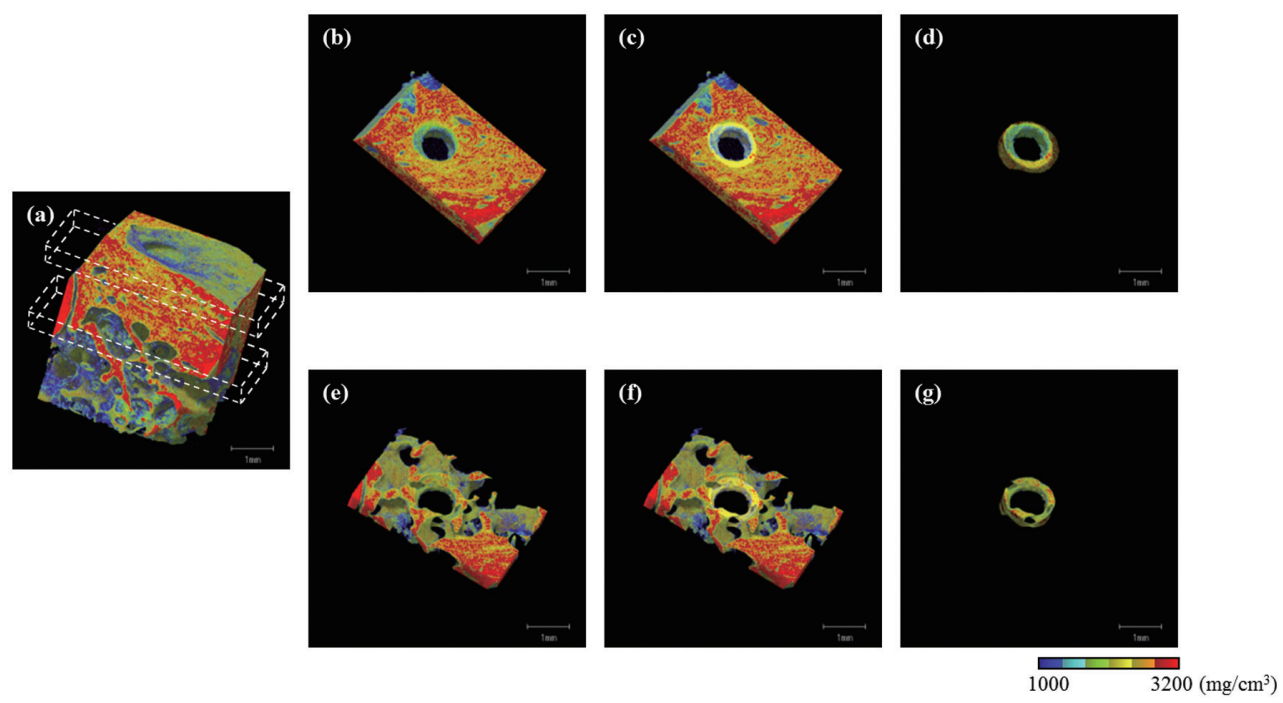

Fig. 3 (a) $\mu \mathrm{CT}$ scanning image after color mapping; (b) Cortical bone layer with $500 \mu \mathrm{m}$ thickness; (c) Selected area with 100- $\mu \mathrm{m}$ thickness of the bone surface in contact with the miniscrew implant; (d) Extracted ring-like cortical bone; (e) Trabecular bone layer with 500- $\mu \mathrm{m}$ thickness; (f) Selected area with $200-\mu \mathrm{m}$ thickness of trabecular bone layer from the bone surface contact with the miniscrew implant; (g) Extracted ring-like trabecular bone.

cotton soaked in distilled water during scanning to avoid dehydration of the specimens. Seven grade hydroxyapatite $\left(200-800 \mathrm{mg} / \mathrm{cm}^{3}\right.$ ) (Ratoc phantom hydroxyapatite, Ratoc System Engineering, Tokyo, Japan) and aluminum $\left(1,550 \mathrm{mg} / \mathrm{cm}^{3}\right.$ ) (Ratoc phantom aluminum, Ratoc System Engineering) were used as phantom materials for quantitative analysis of bone mineral density. The resulting two-dimensional images were reconstructed to a three-dimensional (3D) image with a resolution of $1,024 \times 1,024$ pixels and an isotropic voxel side of $5 \mu \mathrm{m}$ using software (TRI-BONE system, Ratoc System Engineering). For color mapping, higher mineralized regions were expressed as a red color, whereas relatively less mineralized areas were blue (Fig. 3a). To evaluate the image of the bone, rectangular layers with $500-\mu \mathrm{m}$ thickness of cortical or trabecular bone (more on the cervical side) along the long axis of the implant hole were trimmed off (Fig. $3 \mathrm{~b}$ and e), and then areas of $100-\mu \mathrm{m}$ thickness (for cortical bone) and $200-\mu \mathrm{m}$ thickness (for trabecular bone) from the bone surface that came in contact with the miniscrew implant were selected (Fig. 3c and f); 3D images of the ring-like bone were obtained (Fig. 3d and g). Areas of $100 \times 250 \times 500 \mu^{3}$ for cortical bone and $200 \times 250 \times 500$ $\mu \mathrm{m}^{3}$ for trabecular bone were analyzed for both compression and tension regions (Fig. 4); values of bone mineral density (BMD), bone mineral content (BMC), and bone volume (BV) were obtained. BMC is defined as the amount of mineral per square centimeter of bone. BV is calculated by total of bone matrix and BMC. $\mathrm{BMD}$ is calculated by $\mathrm{BMC} / \mathrm{BV}$.

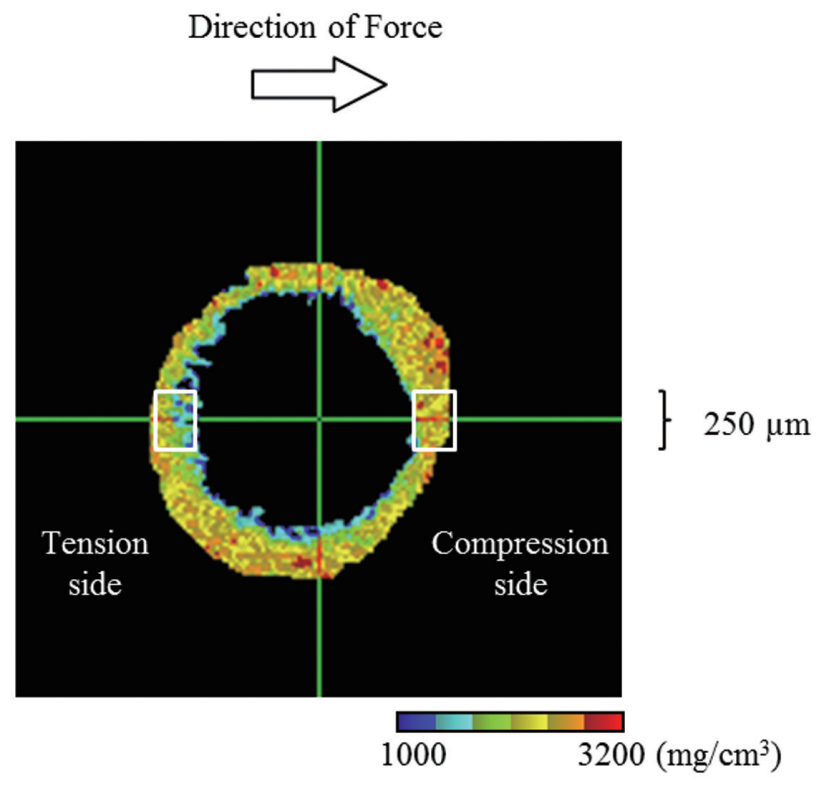

Fig. 4 Areas of $100 \times 250 \times 500 \mu \mathrm{m}^{3}$ for cortical bone and $200 \times 250 \times 500 \mu \mathrm{m}^{3}$ for trabecular bone were analyzed in both the compression and tension regions.

Scanning electron microscopy (SEM) and energy dispersive spectroscopy (EDS)

The surface of the retrieved miniscrew implant was examined by SEM (SSX-550, Shimadzu, Kyoto, 


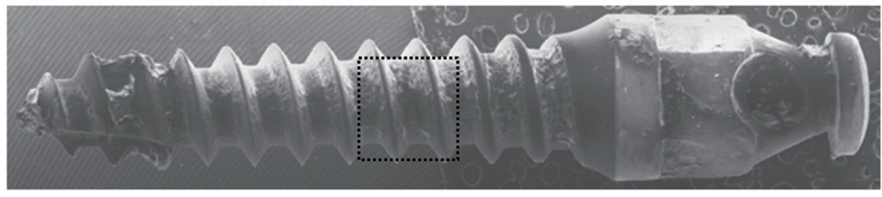

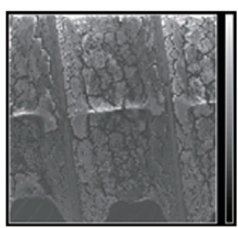

SEM

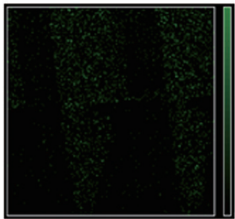

$\mathrm{O}$

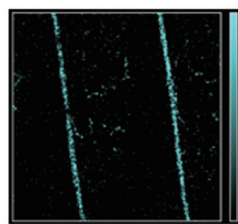

$\mathrm{Ti}$

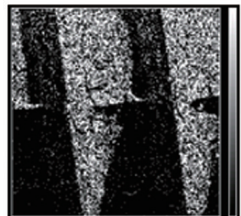

$\mathrm{C}$

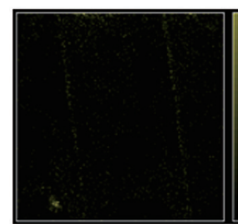

$\mathrm{Al}$

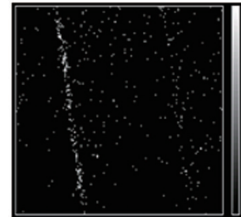

$\mathrm{Ca}$

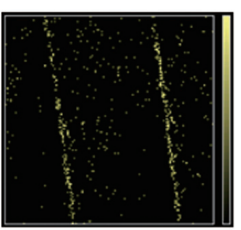

$\mathrm{V}$

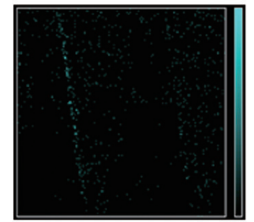

$\mathrm{P}$

Fig. 5 Representative SEM photomicrograph of a retrieved miniscrew implant and compositional maps obtained by EDS.
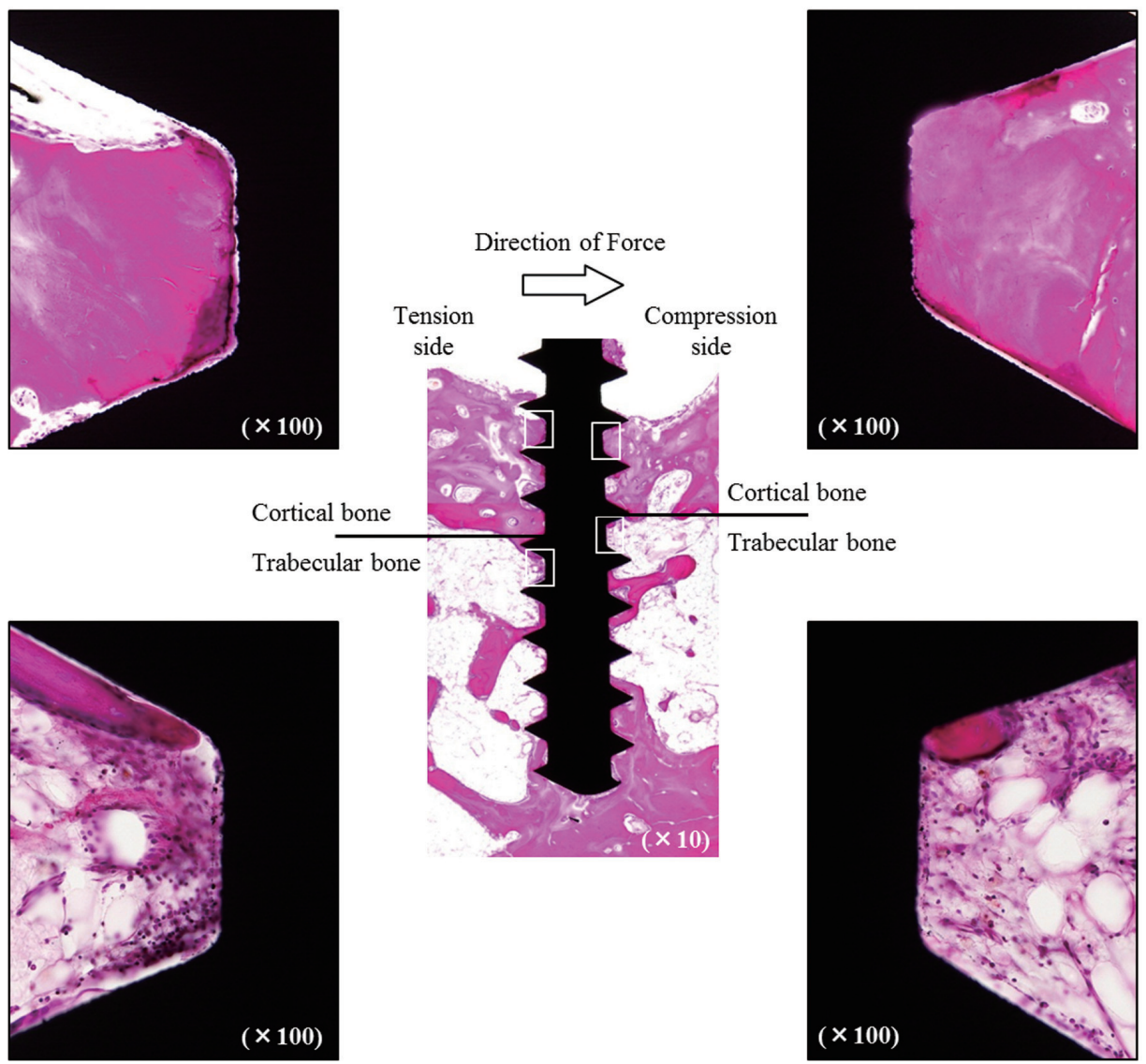

Fig. 6 The measurement regions were $0.5 \mathrm{~mm}$ in length and were located near the border of the coronal side of both cortical and trabecular bones. 
Japan) operating at $15 \mathrm{kV}$, and the composition of the specimen was determined by EDS analysis with a working distance of $15 \mathrm{~mm}$.

\section{Histologic analysis}

Five miniscrew implants were selected for histologic analysis. The bone specimens with miniscrew implants were sectioned to an approximate size of $10 \times 10 \times 10 \mathrm{~mm}^{3}$ using a slow-speed water-cooled diamond saw (Isomet 11-1280, Buehler). The specimens were fixed in $10 \%$ formaldehyde neutral buffer solution for 2 weeks at room temperature and then encapsulated in epoxy resin (Epofix, Struers, Copenhagen, Denmark). Thereafter, specimens including miniscrew implants were sectioned in the longitudinal plane with a micro cutting machine (BS-300, Exakt Advanced Technologies, Hamburg, Germany). The thick slides were ground and polished to about a thickness of $30 \mu \mathrm{m}$ with a microgrinding machine (MG-4000, Exakt Advanced Technologies). The specimens were stained with hematoxylin-eosin and observed under an light microscope. The implant images were quantitatively analyzed using computerassisted image-analysis software (Adobe Photoshop CS2, Adobe Systems, San Jose, California, USA) to calculate the percentage of bone-to-implant contact (BIC) on the compression and tension regions for cortical and trabecular bone (Fig. 6) ${ }^{15-17)}$. For example, $\mathrm{BIC}$ values in the compression region for cortical bone $=$ (the length of the bone and implant contact area in the compression region at the cortical bone) / (the length of the implant interface in the compression region at the cortical bone). The lengths of the measurement regions were $500 \mu \mathrm{m}$, and the regions were located near the border of the coronal side for both cortical and trabecular bone (Fig. 6).

\section{Statistical analysis}

The results were analyzed using the IBM SPSS statistics software (version 19.0J for Windows, IBM, Armonk, NY). The mean BMD, BMC, BV, and BIC obtained from cortical and trabecular bone specimens on the compression and tension sides were compared using the Kruskal-Wallis test and the Mann-Whitney $U$-test with a significance level of $5 \%$.

\section{RESULTS}

All dogs remained in good health during the experimental period, and all miniscrew implants showed initial mechanical stability with no mobility immediately after placement and remained stable for 8 weeks.

The mean BMD, BMC, and $\mathrm{BV}$ obtained by $\mu \mathrm{CT}$ analysis are shown in Table 1 . The compression region in cortical bone showed a significantly higher BMD value (921, $P=0.032$ ) than the tension region (824). Although the compression region showed higher values than the tension region in most other comparisons (BMD for trabecular bone; BMC for cortical bone; BV for cortical and trabecular bones), there was no significant difference in the values.

A representative SEM photomicrograph of the retrieved miniscrew implant and qualitative compositional maps obtained by EDS of the surfaces of the miniscrew implant are shown in Fig. 5. Some deposition was observed on the surface of the miniscrew implant specimen. In addition to a small amount of titanium, vanadium, calcium, and phosphorus, a large amount of carbon was detected by EDS on the surfaces of the retrieved miniscrew implant.

The mean BIC values in cortical and trabecular

Table 1 The mean BMD, BMC, and BV obtained by $\mu \mathrm{CT}$ analysis

\begin{tabular}{|c|c|c|c|c|c|c|}
\hline & \multirow{2}{*}{ Bone type } & \multicolumn{2}{|c|}{ Tension region } & \multicolumn{2}{|c|}{ Compression region } & \multirow{2}{*}{$P$-value } \\
\hline & & Mean & S.D. & Mean & S.D. & \\
\hline \multirow{2}{*}{ BMD } & Cortical bone & 823.72 & 51.25 & 921.28 & 54.97 & 0.032 \\
\hline & Trabecular bone & 821.86 & 149.41 & 835.88 & 81.72 & 0.917 \\
\hline \multirow{2}{*}{$\mathrm{BMC}$} & Cortical bone & $1.10 \times 10^{-2}$ & $5.82 \times 10^{-3}$ & $1.72 \times 10^{-2}$ & $5.24 \times 10^{-3}$ & 0.056 \\
\hline & Trabecular bone & $6.82 \times 10^{-3}$ & $5.67 \times 10^{-3}$ & $6.58 \times 10^{-3}$ & $3.26 \times 10^{-3}$ & 0.917 \\
\hline \multirow{2}{*}{ BV } & Cortical bone & $1.32 \times 10^{-5}$ & $6.84 \times 10^{-6}$ & $1.85 \times 10^{-5}$ & $4.98 \times 10^{-6}$ & 0.310 \\
\hline & Trabecular bone & $7.44 \times 10^{-6}$ & $5.05 \times 10^{-6}$ & $7.66 \times 10^{-6}$ & $3.60 \times 10^{-6}$ & 0.841 \\
\hline
\end{tabular}

Table 2 Mean BIC values in tension and compression regions

\begin{tabular}{|c|c|c|c|c|c|c|}
\hline & \multirow{2}{*}{ Bone type } & \multicolumn{2}{|c|}{ Tension region } & \multicolumn{2}{|c|}{ Compression region } & \multirow{2}{*}{$P$-value } \\
\hline & & Mean & S.D. & Mean & S.D. & \\
\hline \multirow{2}{*}{$\mathrm{BIC}$} & Cortical bone & 73.23 & 6.69 & 74.21 & 5.99 & 0.690 \\
\hline & Trabecular bone & 63.21 & 5.55 & 64.93 & 5.52 & 0.421 \\
\hline
\end{tabular}


bone in the tension region and compression region are summarized in Table 2. There was no significant difference in $\mathrm{BIC}$ between the two specimen groups in cortical and trabecular bone.

\section{DISCUSSION}

To investigate the effects of loading of the miniscrew implant on the bone response, previous histological studies have compared bones in the compression and tension regions, in addition making comparisons with unloading specimens. Histologic analysis by Chen et $a l .{ }^{15)}$ showed that remodeling and bone apposition were slightly more active in the loaded specimens than the unloaded specimen. Majzoub et al. ${ }^{13)}$ reported slight bone apposition in the compression region but not in the tension region. Aldikaçti et al. ${ }^{22)}$ showed a corticalization of trabecular bone in the loaded compared to the unloaded specimen. The tendency of these research findings was that bone responses, such as remodeling and apposition, were slightly activated by loading, although loading did not affect osseointegration when compared quantitatively using BIC (bone-to-implant contact) values. The results of the present study indicated that bone mineralization was significantly higher in the compression region of cortical bone compared to the tension region. The results support previous findings mentioned above. Therefore, immediate loading of miniscrew implants may help to activate bone remodeling and increase the mineral content at the loaded region.

For $\mu \mathrm{CT}$ analysis, this study performed bone density analysis using a BMD calibration standard with seven-grade hydroxyapatite as a phantom material because the method has great advantages for evaluating bone quality more accurately compared with the method with Hounsfield units ${ }^{20}$. In a recent study by Massey et $a l .{ }^{21)}$, the miniscrew implants were not removed during $\mu \mathrm{CT}$ scanning, and the authors excluded the first voxel (from 0 to $6 \mu \mathrm{m}$ from the miniscrew implant) from their analysis due to the metallic halation artifacts. In contrast, in the present study the miniscrew implants were carefully removed from the mandibular bone before $\mu \mathrm{CT}$ scanning to avoid the issue of metallic halation artifacts. The surface of the retrieved miniscrew implant was studied by SEM and EDS; some deposition was observed on the surface of the miniscrew implant specimen. We expected that bone-like structure was formed on the miniscrew implant, although elemental analysis by EDS confirmed that the deposition was contamination, which contains mainly carbon. Therefore, there was no loss of bone to remove the miniscrew implant during specimen preparation in $\mu \mathrm{CT}$ analysis in the present study, meaning that the bone regions analyzed contained real bone surfaces.

In the present study, the values of BMD, BMC, and BV were higher for the compression region of cortical bone than the tension region, although the difference was not significant for BMC and BV. Massey et $a l .{ }^{21)}$ investigated bone adaptation around miniscrew implants and reported significantly greater bone volume fraction around loaded miniscrew implants in the noncortical regions, while the bone volume fraction of cortical bone around unloaded miniscrew implants was significantly greater than the bone volume fraction around loaded miniscrew implants. One of the reasons for the inconsistency may be the use of a different experimental design that caused differences in the center of rotation (CRot) of the miniscrew implant tipping force. The location of the CRot is variable and depends largely on the design of the miniscrew implant and the location where orthodontic force is applied.

Serra et al. ${ }^{16)}$ studied sequential bone healing of immediately loaded miniscrew implants and reported that there was no significant difference in BIC values between the compression and tension regions, although the values increased with healing time. Similarly, the mean BIC values in cortical and trabecular bone in the tension and compression regions in the present study were similar, suggesting that immediate loading of miniscrew implants did not affect osseointegration. An adequate healing period for osseointegration in humans is assumed to be 12 weeks. ${ }^{23)}$. The present study used beagle dogs with an age of 10-15 months, and the dogs were sacrificed 8 weeks after miniscrew implant placement, since bone formation in dogs has been estimated to be approximately twice that of humans and remodeling is much faster than in humans. ${ }^{21)}$. Since the physiological age of the dogs used in the present study corresponded to approximately 13-18 years, the bone response results may differ slightly from those in adult dogs.

\section{CONCLUSIONS}

Under the conditions of this study, the following conclusions can be drawn:

- The bone mineralization of the compression region of cortical bone was significantly higher than that of the tension region.

- The mean BIC values in cortical and trabecular bone at tension and compression regions were similar.

- Immediate loading does not inhibit osseointegration of miniscrew implants but may stimulate bone mineralization.

\section{ACKNOWLEDGMENTS}

The authors thank Nobuhito Nango at Ratoc System Engineering for expert technical assistance with the $\mu \mathrm{CT}$ analysis.

\section{REFERENCES}

1) Roberts WE, Smith RK, Zilberman Y, Mozary PG, Smith RS. Osseous adaptation to continuous loading of rigid endosseous implants. Am J Orthod 1984; 86: 95-111.

2) Kanomi R. Mini-implant for orthodontic anchorage. J Clin Orthod 1997; 31: 763-767. 
3) Miyawaki S, Koyama I, Inoue M, Mishima K, Sugahara T, Takano-Yamamoto T. Factors associated with the stability of titanium screws placed in the posterior region for orthodontic anchorage. Am J Orthod Dentofacial Orthop 2003; 124: 373378.

4) Park HS, Jeong SH, Kwon OW. Factors affecting the clinical success of screw implants used as orthodontic anchorage. Am J Orthod Dentofacial Orthop 2006; 130: 18-25.

5) Kuroda S, Yamada K, Deguchi T, Hashimoto T, Kyung HM, Takano-Yamamoto T. Root proximity is a major factor for screw failure in orthodontic anchorage. Am J Orthod Dentofacial Orthop 2007; 131 Supp 1: S68-S73.

6) Schätzle M, Männchen R, Zwahlen M, Lang NP. Survival and failure rates of orthodontic temporary anchorage devices: a systematic review. Clin Oral Implants Res 2009; 20: 13511359 .

7) Morarend C, Qian F, Marshall SD, Southard KA, Grosland NM, Morgan TA, McManus M, Southard TE. Effect of screw diameter on orthodontic skeletal anchorage. Am J Orthod Dentofacial Orthop 2009; 136: 224-229.

8) Lemieux G, Hart A, Cheretakis C, Goodmurphy C, Trexler S, McGary C, Retrouvey JM. Computed tomographic characterization of mini-implant placement pattern and maximum anchorage force in human cadavers. Am J Orthod Dentofacial Orthop 2011; 140: 356-365.

9) Pickard MB, Dechow P, Rossouw PE, Buschang PH. Effects of miniscrew orientation on implant stability and resistance to failure. Am J Orthod Dentofacial Orthop 2010; 137: 91-99.

10) Motoyoshi M, Uemura M, Ono A, Okazaki K, Shigeeda T, Shimizu N. Factors affecting the long-term stability of orthodontic mini-implants. Am J Orthod Dentofacial Orthop 2010; 137: 588. e1-5.

11) Huja SS, Litsky AS, Beck FM, Johnson KA, Larsen PE. Pullout strength of monocortical screws placed in the maxillae and mandibles of dogs. Am J Orthod Dentofacial Orthop 2005; 127: 307-313.

12) Motoyoshi M, Inaba M, Ono A, Ueno S, Shimizu N. The effect of cortical bone thickness on the stability of orthodontic miniimplants and on the stress distribution in surrounding bone. Int J Oral Maxillofac Surg 2009; 38: 13-18.

13) Majzoub Z, Finotti M, Miotti F, Giardino R, Aldini NN,
Cordioli G. Bone response to orthodontic loading of endosseous implants in the rabbit calvaria: early continuous distalizing forces. Eur J Orthod 1999; 21: 223-230.

14) Serra G, Morais LS, Elias CN, Meyers MA, Andrade L, Muller C, Muller M. Sequential bone healing of immediately loaded mini-implants. Am J Orthod Dentofacial Orthop 2008; 134: 44-52.

15) Chen Y, Kang ST, Bae SM, Kyung HM. Clinical and histologic analysis of the stability of microimplants with immediate orthodontic loading in dogs. Am J Orthod Dentofacial Orthop 2009; 136: 260-267.

16) Serra G, Morais LS, Elias CN, Meyers MA, Andrade L, Muller C, Muller M. Sequential bone healing of immediately loaded mini-implants: histomorphometric and fluorescence analysis. Am J Orthod Dentofacial Orthop 2010; 137: 80-90.

17) Chen Y, Lee JW, Cho WH, Kyung HM. Potential of selfdrilling orthodontic microimplants under immediate loading. Am J Orthod Dentofacial Orthop 2010; 137: 496-502.

18) Iijima M, Nakagaki S, Yasuda $Y$, Handa K, Koike T, Muguruma T, Saito T, Mizoguchi I. Effect of immediate loading on the biomechanical properties of bone surrounding the miniscrew implants. Eur J Orthod 2013; 35: 577-582.

19) Ikeda H, Rossouw E, Campbell PM, Kontogirogos E, Buschang PH. Three-dimensional analysis of peri-boneimplant contact of rough-surface miniscrew implants. Am J Orthod Dentofacial Orthop 2011; 139: e153-e163.

20) Cha JY, Kil JK, Yoon TM, Hwang CJ. Miniscrew stability evaluated with computerized tomography scanning. Am J Orthod Dentofacial Orthop 2010; 137: 73-79.

21) Massey CC, Kontogirogos E, Taylor R, Opperman L, Dechow P. Effect of force on alveolar bone surrounding miniscrew implants: A 3-demensional microcomputed tomography study. Am J Orthod Dentofacial Orthop 2012; 142: 32-44.

22) Aldikaçti M, Açikgöz G, Türk T, Trisi P. Long-term evaluation of sandblasted and acid-etched implants used as orthodontic anchors in dogs. Am J Orthod Dentofacial Orthop 2004; 125: 139-147.

23) Roberts WE, Helm FR, Marshall KJ, Gongloff RK. Rigid endosseous implants for orthodontics and orthopaedic anchorage. Angle Orthod 1989; 59: 247-256. 